\title{
The Effectiveness of Online Synchronous Discussion
}

\author{
Robert A. Schultz \\ Woodbury University, Burbank, CA, USA
}

\author{
bob.schultz@woodbury.edu
}

\begin{abstract}
I have been exploring ways to incorporate online techniques into my MBA course in Management of Information Technology. The course uses small-group discussion of case studies, so online synchronous discussion seemed appropriate. After a small-scale successful experiment, I offered most of the spring 2001 course offering online. Although the students were enthusiastic, I got the disturbing feeling students were not really learning from the online discussions. So I administered a short multiple-choice post-test to the class. I gave the same test to a later class with virtually identical material delivered traditionally. Scores were about $20 \%$ higher for the traditional group, and statistical analysis verifies that this difference is not due to chance. So synchronous online discussion seems less effective than classroom instruction in this context.
\end{abstract}

I suggest possible reasons for the lesser effectiveness of this online technique and consider what other online techniques might be more effective for this material.

Keywords: online instruction, synchronous discussion, threaded discussion, online infrastructure, instructional effectiveness

\section{Introduction}

For the past fifteen years, I have taught a graduate- level MBA course in management of information technology. Although there has been some variation in content in the various versions I have taught, one constant feature has been the use of case studies. In almost all the courses I have taught, smallgroup discussion has played a central role in the examination and analysis of these case studies (see Appendix I). Consequently, when we at Woodbury University began exploring ways to incorporate online techniques into our courses, the classes where small-group discussion figured prominently seemed a potentially good place to start.

I began with the fall 2000 course. We tried one class meeting online; we met synchronously in a commercially available chat room. The experiment worked reasonably well and students were enthusiastic. So we tried a second class meeting, incorporating an electronic "hand-raising" convention which greatly decreased confusion and allowed focused discussion.

On the strength of this experience, I decided to expand the experiment to 11 of the 15 class meetings of the course, for the spring 2001 course offering. Many logistical difficulties (which I will detail below)

Material published as part of these proceedings, either on-line or in print, is copyrighted by Informing Science. Permission to make digital or paper copy of part or all of these works for personal or classroom use is granted without fee provided that the copies are not made or distributed for profit or commercial advantage AND that copies 1) bear this notice in full and 2) give the full citation on the first page. It is permissible to abstract these works so long as credit is given. To copy in all other cases or to republish or to post on a server or to redistribute to lists requires specific permission from the publisher at Publisher@InformingScience.org forced me to reduce the number of online sessions from 11 to 7 . Students were with one exception not much bothered by the relatively severe logistical difficulties. However, I was getting the disturbing feeling that discussion was not growing increasingly sophisticated; in other words, students were not really learning from the online discussions. 
So I prepared and administered a short ungraded multiple-choice post-test to the class. I tallied the results (which intuitively looked to be on the low side) and filed the results away.

I gave the same class with virtually identical material to an almost identical group of students in fall 2001, seven months after the first group. We had only one online session as a demo. The rest of the class sessions (14 out of 15) were in the classroom. The same short multiple-choice post-test was administered to this group, and scores were about $20 \%$ higher. A statistical analysis verifies that this difference is hardly due to chance. Other measures of student ability confirm that the groups were otherwise quite comparable. The tentative conclusion I draw is that, in this context at least, synchronous online discussion was much less effective than classroom instruction.

This paper does not present the results of a rigorous research plan. The study was an afterthought based on information collected in the course of experimenting with online class presentation. Therefore my conclusions are definitely more suggestive than definitive. It seemed worth presenting them in this form because they were striking, because of their potential timeliness and because they might stimulate more careful studies in the same area. Because of limited resources, it is unlikely that I myself will be able to conduct a more rigorous study.

Within these limitations, in the last two parts of the paper, I discuss what might have caused the lesser effectiveness of this online technique. Finally I speculate about what other online techniques might be effective for this material.

\section{The Context}

Woodbury University is a small (1400 students) university in Southern California offering professionally oriented degree programs in business and design. It describes itself as a teaching university, does not award tenure to any faculty, and does not require its faculty to do research unless the research contributes to teaching effectiveness. Resources for traditional research are therefore quite limited. My experimentation with online teaching was the first done within the University. The University at that time had no online teaching infrastructure and in fact still does not supply email accounts to its students.

\section{The Course}

The course in question is currently titled "Management of Information Technology." It has been offered in substantially the same form since 1988, as a required course in our MBA program. Required courses in IT in MBA programs tend to follow one of two different models--either a survey of technology itself or a case-study-driven management course. Our course was of the second type, a case-study management course. Like many of such courses, the text used was authored by Harvard Business School faculty and included case studies developed by the Harvard Business School.

A typical syllabus for the course appears in Appendix I, together with a typical class meeting schedule, both for when the course was delivered in the classroom. Students will arrive at a session ha ving read a chapter from the text and prepared a short paper on one of two cases, determining whether it is a success story or a problem case: If a problem case, what is the problem and what might be a solution; If a success story, what was done right. After a short discussion of assigned material, usually a chapter in the text covering topics such as strategic factors in IT management or outsourcing, two case studies are examined separately. For each, a preliminary discussion establishes the basic facts of the case and sets a question to be answered. Small groups (three to five students) then try to arrive at a solution based on their work in their short papers. After the small groups have reached conclusions, the entire class meets to compare notes and arrive at a consensus. Assignments for the next week are given at the very end of the class. 
At the end of the course, students apply the techniques learned by examining these cases to a case of their own choosing, often one from their own work experience.

The course structured in this way typically receives very high student evaluations.

\section{Changes in the Online Version}

Within the regular classroom format, I began experimenting with doing the class online with synchronous discussion groups replacing the in-class discussion. The rationale was that because so much of class learning took place in the discussion groups, those could easily be translated to an online format. My initial experiment with one online class in Fall 2001 was so enthusiastically received by the students that we did a second class online. This class was also enthusiastically received. Basically the regular class agenda (see Appendix II) was followed, with class discussion of reading material replaced by an online summary to be read before class. The actual class sessions were conducted at the same time as the regular course, but everyone was at a computer, many at home, and logged into a chat room on the free HotOffice site. (Various other ways of accomplishing synchronous communication were tested and discarded for technical and practical reasons; for example, response time for many popular chat programs was too slow to allow discussion. Within the University, both at this time and for the later class, there were no online facilities or infrastructure available.) Instructions for each session were provided in the preceding classroom class as well as online.

As I stated in the introduction, for the spring 2001 course offering I decided to expand the experiment to 11 of the 15 class meetings of the course. The original schedule called for 11 online class sessions out of 15. The free facility that I intended to use, HotOffice, drastically reduced its functionality, eliminating the synchronous message boards necessary for the class. We tested Egroups, which looked quite functional. Unfortunately, between our test and the actual class, Egroups was acquired by Yahoo, which promptly complicated the formerly very transparent signup and login procedure. Yahoo also removed a feature valuable for our discussion groups, namely displaying a chosen user name; instead, Yahoo displayed email account. Login and setup complications forced a one-week delay of the first online class. Later in the term, Yahoo with no notice reduced (temporarily, as it turned out) the size of the discussion window from 20 lines to 2 lines. Discussion was impossible, and that class had to be cancelled, and we returned to the classroom for our remaining classes. Also, after the Yahoo takeover, it was no longer possible to make contact with anyone at the facility. In the end, only 7 classes were delivered online.

Another unexpected logistic difficulty was handling student papers. As I mentioned above, class discussion was based on a short paper done each week by each student. In the previous experimental session, we had done two submissions by email in a smaller class (8 students). However, repeated submissions at random times into my regular account made it almost impossible to track weekly paper submissions. In the classroom environment, I do not allow late papers, and all papers for one week were collected in one bundle at the end of the class. In the online environment, students could and would submit papers at any time, so several sets of papers would be commingled not only with each other but with other messages. I finally set up a separate email account for papers only and enforced a message name protocol. This worked fairly well, but it came toward the end of the course. I took a few weeks to think through the problem and solution, and then another two weeks to set up another university email account.

Students, surprisingly enough, were very understanding of the logistic difficulties and continued to be enthusiastic about the delivery method. The final evaluations for the course were, with one exception, quite positive. The chances are good that the one very negative evaluation was from the one student very upset about the difficulty in tracking papers. At one point, I was getting 10 email messages a day from this student demanding to know exactly what the grades were on all submitted papers. Unfortunately I could not guarantee accuracy. 
Typical online sessions were scheduled very much like the class sessions: We began with a discussion of the assigned material. I had posted on the website a summary of the assigned material and discussion questions which students were to review. Then we would discuss two cases, again having a general discussion followed by small group discussions in separate chat rooms. The multiple chat room facility had worked quite well in the experimental sessions, but often did not work properly because of the complex security added by Yahoo. The general discussions went reasonably well. We always used a convention discovered in the first experimental class: A student first sends a message with the content 'me', and then waits for me to acknowledge him or her before sending the actual message. (I will call this the me-convention) The me-convention serves a hand-raising function and prevents multiple discussions from overlapping. It is slower, though, especially with student who are slow typists.

In spite of student enthusiasm, I was getting the disturbing feeling that discussion was not growing increasingly sophisticated; in other words, students were not really learning from the online discussions. My perception was that it was much more difficult for me to change the direction of the discussion, especially in an unexpected or somewhat technical direction. As a result, I decided to give a short multiple-choice post test to this class and to repeat the test the next time I offered the course in a traditional format. (The test appears in Appendix III.) Students were told that the test did not affect their grade, and I administered the test in the last class session of the online course (now in the classroom). When I repeated the course in the classroom the next semester, I also administered the identical test in the last session of the course.

\section{The Post-Test}

A comparison of the results of the administration of both tests appears as Appendix IV. Intuitively, a difference in both mean and median of about 1.5 correct answers out of 12 (a greater than 10 percent difference) strongly suggests that the traditional-classroom students did better than the online students. Only one student in the online group answered 8 out of 12 correctly (67\%); none of the online students did any better than this. Whereas, six traditional students (out of 18,33\%) answered eight or better correctly. Fourteen out of 19 online students (74\%) scored 5 or less right ( $40 \%$ or below). Whereas, 12 out of 18 traditional students $(67 \%)$ scored 6 or better right $(50 \%)$.

A student's t-test corroborates these results: The probability these test distributions are due to chance is 0.026, well below .05 .

There were no other obvious differences between the two student groups. In fact, the grade distributions were so similar that further analysis did not seem to be necessary. Grades in both classes were based on the same combination of short and final papers. Also, especially over short periods of time (two to four years), the profile of students in our MBA program is very constant. Thus there is no reason to believe that any factors outside the course delivery influenced the difference in these test results.

Since the test was about basic conceptual material in the course, I believe these results suggest that online delivery of the kind used in this course was significantly less effective in communicating this material to the students.

A more detailed analysis of the test results might be useful, if it is possible to separate out test items based on material covered only in online classes from those covered in regular classes. If my tentative conclusion is correct, one would expect the scores for online-class-related material to be lower than scores for material covered in class, even for students in the (mostly) online class. 


\section{Conclusions}

\section{Reasons for the Lesser Effectiveness of On-Line Delivery}

The results of the post tests in the context of the two classes suggest that there are significant differences between online synchrono us discussion and classroom discussion. Even with the adoption of the meconvention, the instructor is merely one message out of many, without the privileged status of being the center of attention at the front of the classroom. As I noted earlier, it was very difficult to change the direction and topic of discussion. Also, in the small group discussions in the classroom, it was very easy to monitor the discussions to take steps if discussion stalled and also to coordinate the end of the small group discussions. It was much easier for small group discussion to get off track or become ineffective in an online context because moving from group to group was time-consuming and therefore I could not monitor the groups as closely.

There is no question that the logistical and technical difficulties contributed to the poorer performance of the online students. Indeed I strongly recommend using only online facilities dedicated to educational use and with support. (As I mentioned before, these facilities were not available at the time I did these courses.) It is also important to have dedicated email addresses for the students. Woodbury University is unusual in not issuing email addresses to students, and so this added the additional administrative overhead of correcting changed student email addresses and resending email when students changed their email addresses with some frequency.

However, I believe that even if these technical difficulties had not existed, my initial idea of replacing classroom discussion in the context of this course with online synchronous discussion was flawed. I believe the test results suggest that the online discussions were significantly less effective, but I am using my own experience in both contexts to make the diagnosis of what did not work.

\section{Other Possible Online Techniques}

Instructors in programs at institutions with extensive online course programs, for example the University of Phoenix, have told me that synchronous discussions are highly unpopular because they require fixed class times. Students in heavily online programs very much prefer to have flexible schedules. My experiences with synchronous discussion as a method of conveying conceptual material and applying concepts to case study material strongly suggests that synchronous techniques are not as effective as regular classroom discussion. So my experience suggests that eliminating online discussion may not be a great loss.

The value of online synchronous discussion may simply be to allow students to interact with each other and to brainstorm. My results suggest that for any other more structured learning purposes, synchronous discussion may not be effective. In fact, by suggesting that the synchronous discussion is equivalent to class discussion, it may make things worse. I also noted that very few students actually read the posted preparatory material which was in part to be the equivalent of in class discussion of the assigned conceptual material.

I think it is quite possible that other online techniques may be effective in conveying conceptual material and applying concepts to case studies. Threaded discussion, while not superficially equivalent to classroom discussion, offers equivalent or greater potential for monitoring discussion. Also, if the naïve equivale nce of classroom to chat room is given up, it should be easier to get students to accept that reading posted materials is indeed part of the course work rather than a secondary addition.

I would like to continue experimenting with the use of threaded discussion to substitute for in-class discussion. However, the background technical and logistic difficulties at my current university are daunting. Without stable email addresses for students, and without a dedicated stable discussion platform, the 
extra effort involved to mount this experiment makes it very difficult for me to continue my research in this area. It may be better to recommend the effort to those at other universities with more robust support for online education.

\section{Appendix I -- Typical Syllabus for Classroom Delivery. WOODBURY UNIVERSITY Fall $2001 \quad$ Dr. Robert A. Schultz CI 509 MANAGEMENT OF INFORMATION TECHNOLOGY W 6:30p-9:15p}

Examination of the organization and function of information systems in business organizations. The emphasis will be on the management side of information management, rather than the technical side-that is, on what you need to know to make intelligent decisions about managing information resources within your organization.

GRADING: $20 \%$ Attendance \& Participation

$40 \%$ Case Discussions (10)

$12 \%$ Short exercises (3)

$28 \%$ Real Life Report (= Takehome Final)

Attendance and Participation (20\%): You are expected to be on time for regular classes. More than two unexcused absences are unacceptable. One or two classes will be conducted online. You will need to have access to a computer with an internet connection and current web browser, either in the University Computer Lab or at home. You are expected to attend both types of classes, and they will both standardly meet on Wednesdays from 6:30-9:15p.

Case Discussions (40\%): Every week we will discuss one or more cases. You are to read each case (usually from the text). Each case presents either a problem or a description of a situation handled well. Determine which, and formulate your own thoughts about the problem and solution, or about what was handled well and why. There will be much class discussion based on the cases. Turn in a maximum of 2 pages per case.

(Note: late homework WILL NOT be accepted but may be excused. Also, for online classes, papers will be submitted by email.)

Real Life Report (33\%): Each class member will be expected to do a 5-to-8 page case report on a case of their own choice. Cases should be similar to those used in the text, ideally concerning an organization you are personally familiar with. A case reported in the media is acceptable, but must be approved by me in advance. In any case, the case should involve a problem in information management in an organization. A two-to-three minute in-class summary will also be required.

Short exercises (12\%): Three are scheduled: You will be expected to locate a current article about IT productivity, write and turn in a two-page summary. You will need to do a 'risk assessment' based on the material in Chapter 11 in the text. You will also need to locate and try out an interesting ecommerce application, and analyze its success or lack of success.

\section{REQUIRED TEXTS:}

$\underline{\text { Corporate Information Systems Management: Text and Cases, }}$

by Cash, McFarlan, et al. FIFTH Edition. Irwin, 1999.

(Be sure to get the hardcover which has the cases.)

LEARNING OUTCOMES: By the end of this course you will:

Be able to do an IT management audit; that is, you will be able to comment intelligently on a wide range of problems involved in the management of information in an organization, such as 
managing technological change, competitiveness, benefits and threats of IT in organizations, risk management, IT architectural issues, transnational IT issues, IT planning, e-commerce.

INSTRUCTOR CONTACT INFO: X297; Email: bob.schultz@woodbury.edu

COURSE WEB PAGE: http://roadrunner.woodbury.edu/courses/schultz/ci509

TOPICS AND SCHEDULE:

Class Date $\quad \underline{\text { Topic \& Assignment }}$

08/29/01 Introduction to course, requirements, each other, etc. Intro to online class techniques.

SKIM Chs.1\&2. Case method. Review of background. DO one case in class.

09/05/01 READ Ch.3. Strategy \& Competition. DO Case 2.1 or 2.3.

09/12/01 READ Ch.4. Interorganizational systems \& e-Commerce

DO case 3.4 or 5.1

09/19/01 READ Ch.5. IT organization \& control

DO case 3.1 or $3.2+3.3$

09/26/01 READ Ch.6. Managing technological change

DO case 4.4 or $x 4.1,2,3$

10/03/01 READ Ch.7. IT Policy Issues

DO case 1.1 or 2.2

10/10/01 IT Produc tivity--Paradox and Reality

READ Xeroxed material

DO Find \& summarize current article in this area.

Evaluation of online class experience

10/17/01 READ Ch.9. Operations control

DO case 4.3 or 5.3

10/24/01 READ Ch. 10. Operations management.

DO 5.2 or 5.4

10/31/01 READ Ch.8. Outsourcing

DO case 4.1 or 4.2

11/07/01 Project Development \& its Management.

READ Selections.

11/14/01 READ Ch.11. Risk.

DO Risk assessment of case 4.4 and any one other case.

11/21/01 E-Commerce revisited (online class)

DO find an innovative service delivered over the Internet. Use the service, report on where it is, analyze why it is or is not successful. Write this up in 1 to 3 pages.

11/28/01 READ Ch.12. Transnational IT.

DO case x12.2 or a report on relevant IT differences between the U.S. and a country whose IT infrastructure you are familiar with Report summaries. Ungraded quiz.

12/12/01 7pm Final Papers due

\footnotetext{
Typical class session (in classroom)

6:30 Agenda

6:40 Return papers

6:50 current IT developments (class volunteers)

7:00 discussion of readings assigned for class

$7: 35$ break

7:50 First case discussion--setup

8:00 Small group discussion

8:20 Summary discussion
} 
8:30 Second case discussion--setup

8:40 Small group discussion

9:00 Summary discussion

9:10 next assignments

\title{
Appendix I-Changes in Syllabus for online class
}

(material added for online delivery is in bold)

\author{
GRADING: $20 \%$ Attendance \& Participation \\ $40 \%$ Case Discussions (10) \\ $12 \%$ Short exercises (3) \\ $28 \%$ Real Life Report (= Takehome Final)
}

Attendance and Participation (20\%): Depending on how well things go, as many as 10 class sessions will be conducted online. You will need to have access to a computer with an internet connection, plus a current web browser, Netscape 4.x or Explorer 4.x. Although a standard 52k modem connection is adequate, the faster your connection, the better the online experience. You may want to use a computer in the Lab; all machines are connected to the University network and its $\mathrm{T} 1$ internet connection. There will be more discussion of online classes in the first two (regular) class meetings. You are expected to attend both types of classes, and they will both standardly meet on Tuesdays from 6:30-9:15p.

Case Discussions (40\%): Every week we will discuss one or more cases. You are to read each case (usually from the text). Each case presents either a problem or a description of a situation handled well. Determine which, and formulate your own thoughts about the problem and solution, or about what was handled well and why. There will be much class discussion based on the cases. Turn in a maximum of 2 pages per case.

(Note: late homework will not be accepted but may be excused. Also, for online classes, papers will be submitted by email.)

Real Life Report (33\%): Each class member will be expected to do a 5-to-8 page case report on a case of their own choice. Cases should be similar to those used in the text, ideally concerning an organization you are personally familiar with. A case reported in the media is acceptable, but must be approved by me in advance. In any case, the case should involve a problem in information management in an organization. A two-to-three minute in-class summary will also be required.

Short exercises (12\%): Three are scheduled: You will be expected to locate a current article about IT productivity, write and turn in a two-page summary. You will need to do a 'risk assessment' based on the material in Chapter 11 in the text. You will also need to locate and try out an interesting ecommerce application, and report on and analyze its significance.

\section{TOPICS AND SCHEDULE:}

Class Date $\quad \underline{\text { Topic \& Assignment }}$

01/09/01 (in classroom) Introduction to course, requirements, each other, etc. Intro to online class techniques. SKIM Chs.1\&2. Case method. Review of background. DO one case in class.

01/16/01 (in classroom) READ Ch.3. Strategy \& Competition. DO Case 2.1 or 2.3. Setup for online classes.

01/23/01 (online class) READ Ch.4. Interorganizational systems \& e-Commerce 
DO case 3.4 or 5.1 (actually held in classroom)

01/30/01 (online class) READ Ch.5. IT organization \& control

DO case 3.1 or $3.2+3.3$

02/06/01 (online class) READ Ch.6. Managing technological change

DO case 4.4 or $\mathrm{x} 4.1,2,3$

02/13/01 (online class) READ Ch.7. IT Policy Issues

DO case 1.1 or 2.2

02/20/01 (in classroom) IT Productivity--Paradox and Reality

READ Xeroxed material

DO Find \& summarize current article in this area.

Evaluation of online class experience

02/27/01 (online class) READ Ch.9. Operations control

DO case 4.3 or 5.3

03/06/01 (online class) READ Ch. 10. Operations management.

DO 5.2 or 5.4

03/13/01 spring break

03/20/01. (online class) READ Ch.8. Outsourcing

DO case 4.1 or 4.2

03/27/01 (online class) E-Commerce revisited

DO find an innovative service delivered over the Internet. Use the service, report your experience, analyze the usefulness of the service. Write this up in 1 to 3 pages.

04/03/01 (online class) Project Development \& its Management.

READ Selections.

04/10/01 (online class) READ Ch.11. Risk. (cancelled, rescheduled in classrom 4/17)

DO Risk assessment of case 4.4 and any one other case.

04/17/01 (online class) READ Ch.12. Transnational IT. (rescheduled in classroom 4/24)

DO case $\mathrm{x} 12.2$ or a report on relevant IT differences

between the U.S. and a country whose IT infrastructure you are familiar with Professors online from Japan may participate in this class and possibly others.

04/24/01 (in classroom) READ Ch. 13. The IT Business. (included material from 4/17)

Report summaries. Evaluation of online class experience

05/01/01 7pm Final Papers due

\section{Appendix III- Post Test}

(The identical quiz was given at the end of the online and the regular classes)

\section{Ci 509 spring 2001 Final quiz (Ungraded)}

Closed book, closed note, closed neighbor 
Name:

Choose the one best answer. Circle the letter of your choice.

1. The three "eras" of computing are:
a. scientific, business, intemet
b. mainframe, pcs, networked
c. manual, automated, Microsoft
d. apple, IBM, Dell

2. The four categories of strategic relevance are:
a. Support, Marketing, Construction, and Strategic
b. Support, Factory, Turnaround, and Strategic.
c. Low Impact, Factory, Turnaround, and High Impact
d. Construction, Implementation, Operation, and Maintenance

3. The strategic position of IT in an organization makes a significant difference in how IT is managed in the following area:
a. Operations
b. Risk Management
c. Global IT management
d. All of the above

4. The text views e-commerce as a combination of
a. Interorganizational Systems and the Internet
b. The world wide web and TCP/IP
c. Channel management and the World Wide Web
d. Interoganizational Systems and venture capital

5. IT staff/user/management balance
a. is easy to achieve if you have a good strategic plan
b. requires management to take an active role
c. is best accomplished by paying attention to user needs
d. is best accomplished by having knowledgeable IT staff make the important decisions.

6. The Nolan Phase Model has:
a. Two phases, high risk and low risk
b. Four phases, project feasibility, analysis and design, development, and maintenance.
c. Four phases, project initiation, technology learning, rationalization, and technology transfer.
d. Two phases, development and control

7. The Nolan Phase Model recommends different management controls at different stages of a project because:
a. Tight controls at the beginning of a project may stifle innovation
b. Loose controls towards the end of a project may result in inefficient operations
c. Both a. and b.
d. Risk management requires it.

8. The most significant change in the way inventory is managed by companies such as WarMart is:
a. Suppliers control inventory level
b. IT is used to determine customer preferences
c. Inventory is supplied just in time
d. Scanners are used to track inventory

9. Which of the following is NOT a good reason for outsourcing:
a. Cost savings
b. Poor inhouse IT performance
c. Downsizing the company's operations 
d. Inability to get and retain IT staff with necessary skills

10. When a unit has confficting demands for service, a good solution is:
a. Tell everyone to work harder
b. Ignore one of the demands
c. Increase the budget of the service unit.
d. Split the service unit into two different units with non-confficting responsibilities

11. Four commonly discussed solutions to the Productivity Paradox are:
a. Poor training, obsolete equipment, mismeasurement, redistribution
b. Mismeasurement,, Mismanagement, Miseducation, Mistakes
c. Mismeasurement, Lag, Mismanagement, Redistribution
d. Inefficiency, Poor training, Mismeasurement, Redistribution

12. The three components used to predict project implementation risk are:
a. size, experience with technology, structure
b. size, strategic importance, structure
c. size, experience with technology, strategic importance
d. quality of development group, experience with technology, structure

\section{Appendix IV--Post Test Results}

Spring 02 questionnaire

(online class)

\#students

\#right at level cumulative

$32 \quad 2$

$\begin{array}{lll}4 & 3 & 5\end{array}$

$\begin{array}{lll}5 & 8 & 13\end{array}$

$\begin{array}{lll}6 & 4 & 17\end{array}$

$\begin{array}{lll}7 & 1 & 18\end{array}$

$8 \quad 1 \quad 19$

90

$10 \quad 0$

110

120

total 19

$$
\mathrm{n}=19,12 \text { questions }
$$

ave score $\quad 5.11$

median $\quad 5.00$

std $\quad 1.74$

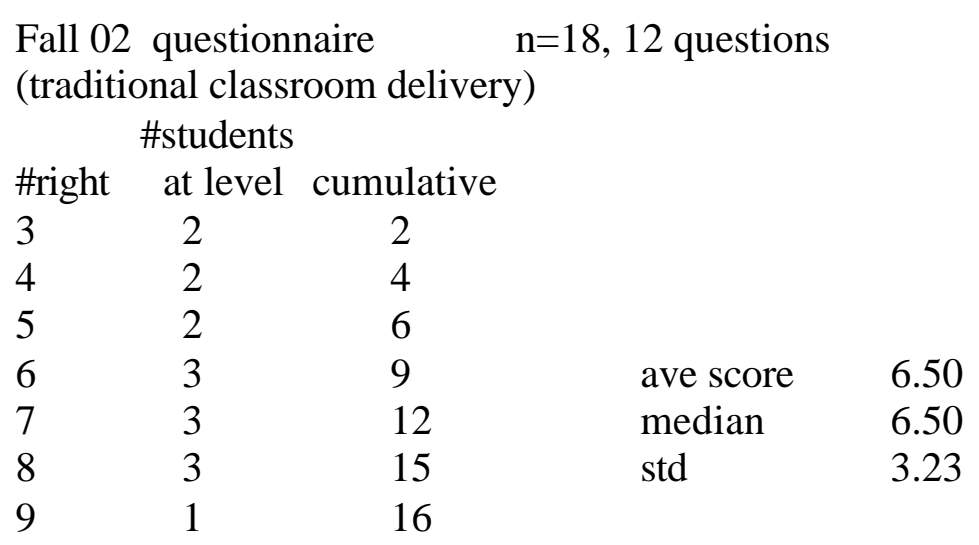


Effectiveness of Online Synchronous Discussion

$\begin{array}{lll}10 & 1 & 17\end{array}$

$\begin{array}{lll}11 & 1 & 18\end{array}$

120

total 18 